\title{
Monitoring of the Environment around Kagoshima Bay Using Remote Sensing Data -Development of the Identifying Method for Seaweeds Growing Region-
}

\author{
Etsuji ISHIGURO*, Shin-ichiro YOSHIMOTO*, Daitaro ISHIKAWA*, \\ Hiroyuki KIKUKAWA ${ }^{* *}$, and Tadahide NORO ${ }^{* *}$ \\ *Faculty of Agriculture, Kagoshima University, 1-21-24 Korimoto, Kagoshima, 890-0065, Japan \\ **Faculty of Fisheries, Kagoshima University, 4-50-20, Shimoarata, Kagoshima 890-0056, Japan
}

\begin{abstract}
This study was conducted to provide data, and used to investigate the cause of environmental changes on the seashore, in particular the cause of "iso-yake", deforested areas in marine environments. Our efforts were then focused on establishing a method of identifying seaweed-growing region using remote sensing data collected by satellites and aerial photographs.

Spectral reflectance on the rocks and the seaweed grown at several sea depths were measured with a handheld spectroradiometer. It was found that mean spectral reflectance values corresponding to Landsat/TM bands exponentially decreased with the increase in distance between the top of the seaweed and the sea surface. The mean spectral reflectance values corresponding to Red (R), Green (G) and Blue (B) regions showed the same tendency Landsat/TM. The indices, $\mathrm{ND}_{32}$ and $\mathrm{ND}_{\mathrm{RG}}$, were reached by making full use of the sea-truth data.

The pass radiance and the extinction coefficients in the sea were taken into account and the surface reflection was corrected by subtracting the deep sea region data. Finally, seaweed-growing regions were identified from the Landsat/TM data and the aerial photograph with each ND-index, respectively and these images were confirmed with the sea truth data.

In this study, we developed an algorithm to identify the seaweeds growing regions from satellite data and aerial photographs and confirmed its accuracy. We expect that the methods based on the algorithm will give a solution to clarify the cause of environmental changes on the seashore.
\end{abstract}

Keywords: Aerial photograph, Identifying seaweed-growing regions, Iso-yake, Landsat/TM data, Radiation transmittance of sea water

\section{Introduction}

The seashore environment is being changed dramatically through increases in human activities. Satellite observation is advantageous for seashore monitoring, because it enables the periodic surveying of data over a large area. The plausibility of monitoring seashores by remote sensing, i.e., distribution of turbidity and seawater depth, has been investigated.

The Kagoshima Bay has two deep basins and is almost closed. The water mass exchange occurs mainly through density flow and the occasional ocean water intrusion in winter, there is the possibility, however, that the exchange is insufficient. The quality of water in the bay has become worse due to high nutrients, especially phosphorus. The areas where seaweed grows provide places to lay eggs for fish or shelters for small fish. It is thought that the disappearance of seaweed is caused by the consumption of sea urchins or crabs and by environmental changes, i.e., high nutrients and water temperature. However, these causes have not been elucidated yet.

Since these regions in the bay could reflect the environmental changes, Kagoshima University launched a university-wide project. Four faculties joined the project; the faculties of Fisheries, Medicine, Engineering and Agriculture. In the project, an intensive investigation of "iso-yake", deforested areas in marine environments, in Kagoshima Bay was carried out. The roles of the remote sensing group in the project were to 
establish identification methods of seaweeds growing areas using satellites and aerial photographs and to analyze the changes in those areas.

As the satellite data present the data over a large area periodically, investigation of coastal environment, i.e., turbid distribution in the coastal area (Uda et al., 1988; Bierwirth et al., 1993; Jun and Gotoh, 1993), identifying coral (Kayane, 1992; Luczkovich et al., 1993; Kayane et al, 1994; Matsunaga et al., 1999), estimation of sea depth (Ishiguro et al., 2001; Yamano et al., 2003), distribution of geological features and plankton (Fujii et al., 2000; Brown et al., 1995; Sakuno et al., 2001; Oki et al., 2001), and measuring flow speed (Matsunaga et al., 1999), were studied.

Our study focused on developing and establishing the identification methods of seaweed-growing areas using satellites and aerial photographs and to provide data for clarifying the cause of environmental changes on the seashore.

\section{Materials and Methods}

\subsection{Materials}

Satellite data and aerial photographs were used to identify the seaweeds growing areas. Types of satellite data were reviewed on the points of spatial resolution, monitoring period, and ease of obtaining the data. Landsat-5/TM (Path-Row: 112-38) taken on 16 May, 1996, and 17 April 1997, were used for the analysis. On the other hand, aerial photographs, which were taken on 26 May 2003, of the coastal zone of Kasari Town in Kagoshima Prefecture, were also analyzed.

\subsection{Methods}

\subsubsection{Sea truth}

Oki-kojima and Kaminose-jima islands in the Kagoshima Bay were examined as a sea truth in the spring of 2003. In these regions, the spectral reflectances of seaweed (c.v., Mamedawara) and rocks were measured with a handheld spectrometer (ELM Co., Japan, measuring region is from $400 \mathrm{~nm}$ to $1,100 \mathrm{~nm}$ with $3 \mathrm{~nm}$ intervals). Observation points were selected as a function of sea depth of rocks and seaweeds below sea surface.

In the case of seaweed, the depths were $10 \mathrm{~cm}$ to $80 \mathrm{~cm}$ with $10 \mathrm{~cm}$ intervals, and in the case of rocks, the sea depth were $10 \mathrm{~cm}$ to $60 \mathrm{~cm}$.

\subsubsection{Image Analysis}

ERDAS IMAGINE, image processing software, was used to process the data.

(1) Pedestal procedure (Japan Association on
Remote Sensing, 1993)

Satellite data involve several effects, such as pass radiance. This pass radiance was expressed as the highest brightness values of no-pixels in each band histogram. This value is called the pedestal value and differed with the band and observing data. If the pedestal value was subtracted from the original brightness of each band respectively, the effects of pass radiance in the satellite data are reduced.

(2) Transfer from the digital number to radiation (Japan Association on Remote Sensing, 1993)

The following equation has been proposed by NASA.

$$
L_{\lambda \mathrm{R}}=\left(V / D_{\mathrm{Max}}\right)\left(R_{\lambda \mathrm{Max}}-R_{\lambda \mathrm{Min}}\right)+R_{\lambda \mathrm{Min}}
$$

where $L_{\lambda R}$ is radiation, $V$ is digital number, $D_{\operatorname{Max}}$ is 255 , and $R_{\lambda \text { Max }}$ and $R_{\lambda \text { Min }}$ are the maximum and the minimum values of detector. These values differ with satellite sensors as reported by NASA.

(3) Transfer from radiation to reflectance (Japan Association on Remote Sensing, 1993)

Following equation has also been proposed, by NASA.

$$
\rho_{\lambda}=\left(\pi \cdot L_{\lambda \mathrm{R}} \cdot d^{2}\right) /\left(E_{\mathrm{sun \lambda}} \cdot \cos \theta_{\mathrm{s}}\right)
$$

where $\rho_{\lambda}$ is the reflectance, $d$ is a average distance between the sun and the Earth, $E_{\text {sunn }}$ is sun constant, $1.37 \times 10^{3} \mathrm{Wm}^{-2}$ and $\theta_{\mathrm{s}}$ is a solar zenith angle.

\section{Results and Discussion}

\subsection{Spectral characteristics of seaweed and rocks}

The characteristics of the spectral reflectance of seaweeds are shown in Fig.1. The distance between the sea surface and the canopy of seaweeds was chose as a parameter. At each depth, the curves have a peak around $575 \mathrm{~nm}$ in the visible region. These tendencies are the same as those of plant grown on the land. However, in the near infrared region, the peak appears around $700 \mathrm{~nm}$, and with increases in the wavelength reflectance decreases.

The mean spectral reflectance corresponded with Landsat TM bands and R-region $(600-700 \mathrm{~nm}), \quad$ G-region $(500-600 \mathrm{~nm})$, and B-region $(400-500 \mathrm{~nm})$ were calculated. The relationships between the mean spectral reflectance and the depth were shown in Figs.2 
and 3. All bands decreased with increases in the depth. They fit well with the data in all bands of visible regions but for the infrared region, Band 4. In the case of aerial, they also fit well in R-, G-, and B-regions. These results suggest the plausibility of the use of Landsat TM data and aerial photographs for the identification of the seaweed.

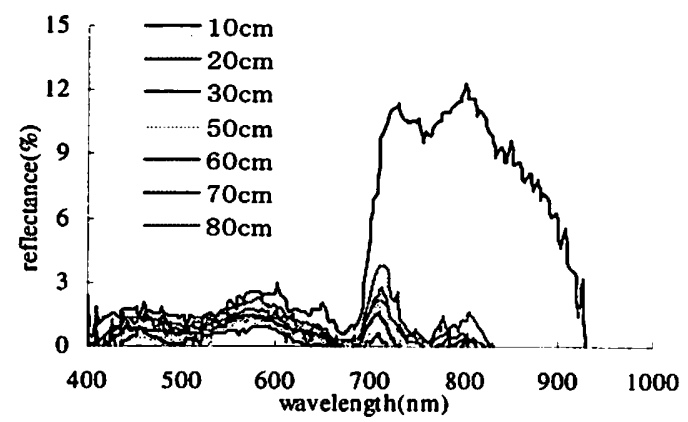

Fig.1. Spectral characteristics of seaweed at each depth.

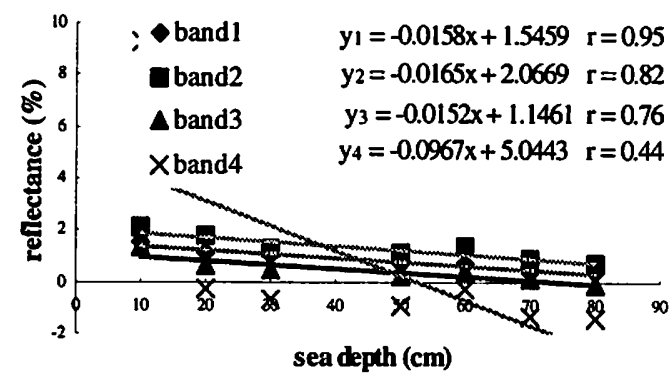

Fig.2. Relationships between the mean reflectance corresponded with L-5/TM bands of seaweed and sea depth.

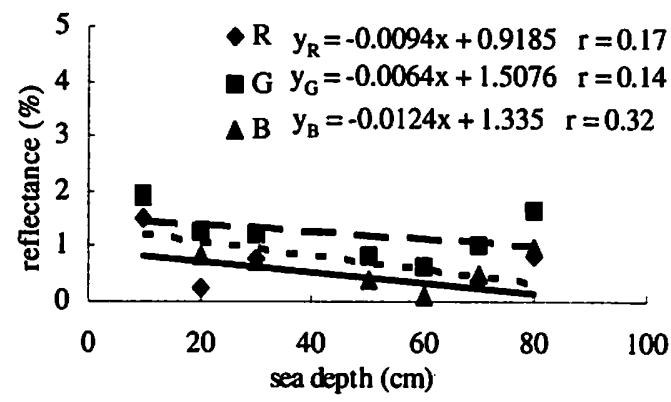

Fig.3. Relationships among the mean reflectance corresponded with R-, G- and B-region of seaweed and sea depth.

The spectral reflectance of rocks located at several water depths is shown in Fig.4. As moss covers on the rocks, the peak of the reflectance appeared around $575 \mathrm{~nm}$, the same as for plants on the ground. The relationships among the mean spectral reflectance for TM bands and R-, G-, and B-regions and sea depths are shown in Figs.5 and 6. In these cases, the values of each mean spectral reflectance and each color region were decreased linearly with increases in the depth. The coefficients of mean spectral reflectance were higher than those of the color.

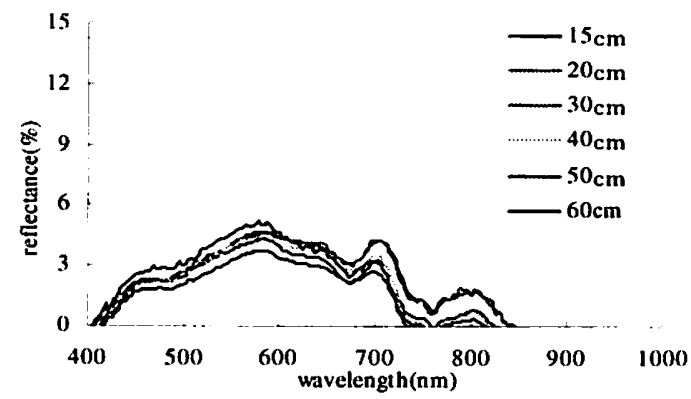

Fig.4. Spectral characteristics of rocks at each

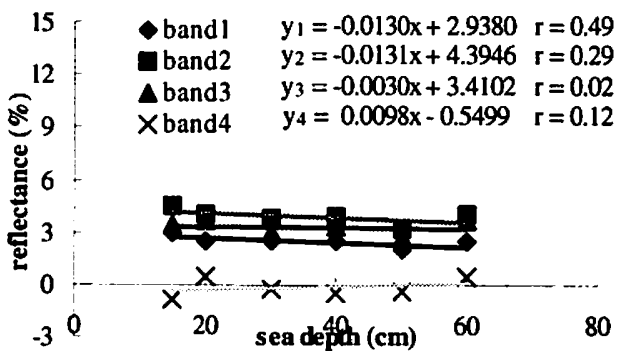

Fig.5. Relationships between the mean reflectance corresponded with L-5/TM bands of rocks and sea depth.

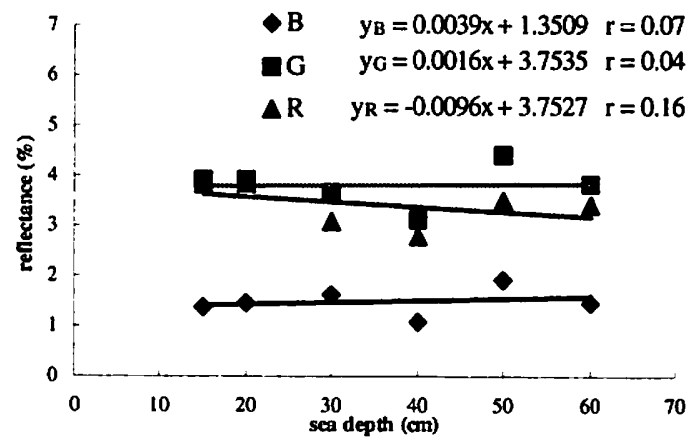

Fig.6. Relationships among the mean reflectance corresponded with R-, G- and B-region of rocks and depth.

\subsection{Analyzing Indices}

The data, i.e., TM band or R-, G-, and B-region, were affected by the atmospheric conditions and the turbidity of the sea water. The indices, consisted with multi bands, were tested with the depth (Fig.7). Among many indices, following indices fit well with the data for the distances.

$$
\begin{array}{ll}
\text { S-ND }{ }_{23}=-0.0165 X+0.9141 & \mathrm{r}=0.93 \\
\mathrm{R}-\mathrm{ND}_{23}=-0.0033 \mathrm{X}+0.2416 & \mathrm{r}=0.88 \\
\text { S-ND } \mathrm{RG}=-0.5466 \mathrm{X}+19.634 & \mathrm{r}=0.91 \\
\mathrm{R}-\mathrm{ND}_{\mathrm{RG}}=-0.0242 \mathrm{X}+7.1437 & \mathrm{r}=0.74
\end{array}
$$

where $\mathrm{ND}_{23}=$ (band3-band2)/(band3+band2) and $N D_{R G}=(R-G) /(R+G), X$ is a distance, and $S-$ and $\mathrm{R}$ - are seaweed and rocks, respectively. 
Comparing the regression equations for $\mathrm{S}-\mathrm{ND}_{23}$ and $\mathrm{R}-\mathrm{ND}_{23}$, the intercepted values of $\mathrm{R}-\mathrm{ND}_{23}$ is higher than that of $\mathrm{S}^{-\mathrm{ND}_{23}}$, and the inclination of $\mathrm{R}-\mathrm{ND}_{23}$ equations is lower than that of S-ND ${ }_{23}$, inversely. Shallower than $30 \mathrm{~cm}$ in depth, seaweed is dominant and below this depth, rocks are dominant. In the aerial photographs, cross-points differ slightly but the tendency is the same. These results showed the possibility of the identification of the seaweed-growing areas by Landsat data or aerial photographs

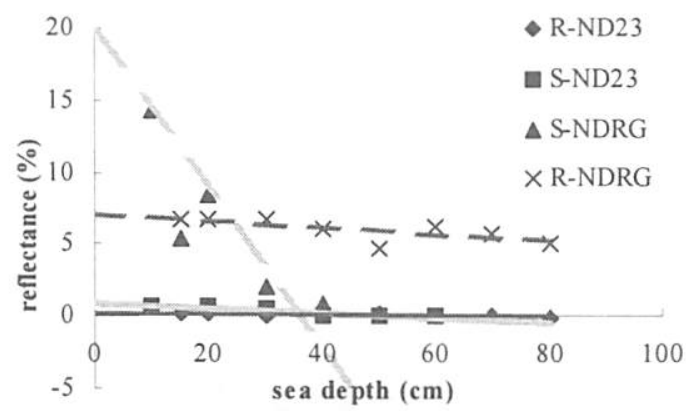

Fig.7. Relationships between the indices and sea depths.

\subsection{Satellite image}

The brightness of each band of Landsat-5/TM, observed on 16th May, 1996, was processed by following procedures, 1) pedestal procedure, 2) transfer from the brightness to radiation and 3) transfer from the brightness to reflectance. Fig. 8 shows an image identifying the Kamise Island and the seaweed-growing spots by $\mathrm{ND}_{23}$ index applied to Landsat-5/TM data. The crescent-shaped white part in the center of this figure is Kamise Island. The dark black spots around the island represent the areas where seaweed grows.

The left of side the island was darker than the right side. From the sea truth, it was confirmed that the brighter part was the region where the seaweed appeared on the sea surface, and the darker part was the region where the canopy of seaweeds did not appear on the sea surface.

It was assumed that the reflected energy at the fully deep sea came from only its sea surface, and the turbidity of the sea water had nothing to do with the depth of the observation spots of the sea. The reflected energy at the shallow region minus that at the deep region would yield only a reflected energy at the sea bottom.

Figure 9 shows the image treated with this energy correction formula. Comparing Fig. 8 and Fig 9, the region where the top of the seaweed was under the sea surface was clearly identified, but the region where the top of the seaweed was over the sea surface was confused with the island.

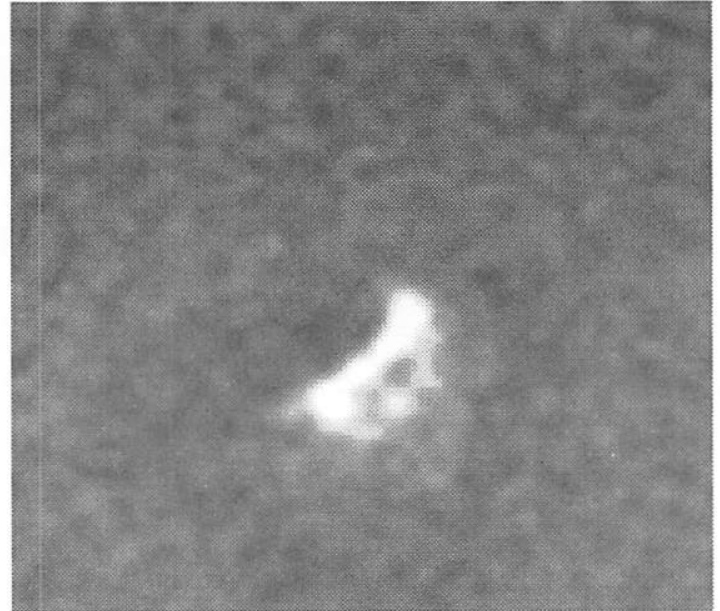

Fig.8. $\mathrm{ND}_{32}$ image treated with pedestal procedure only (L-5/TM: 16 May 1996).

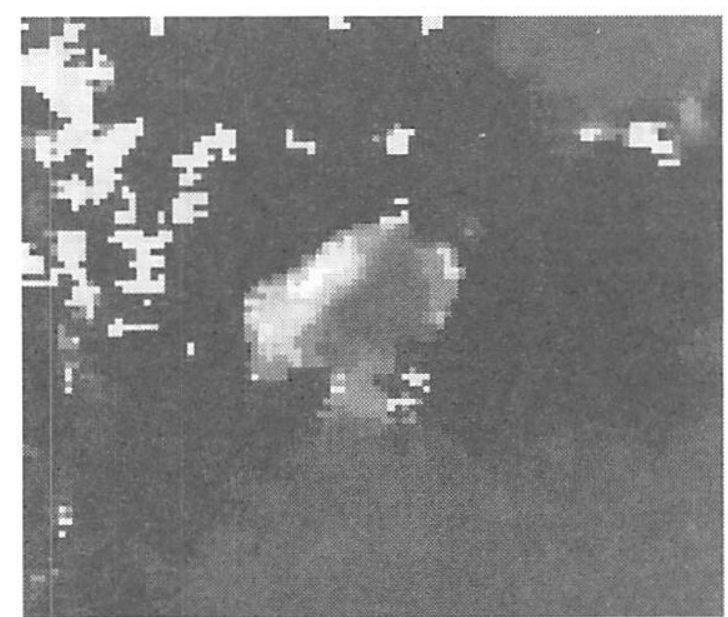

Fig.9. $\mathrm{ND}_{32}$ image treated with pedestal and without the energy reflected from sea surface (L-5/TM: 16 May 1996).

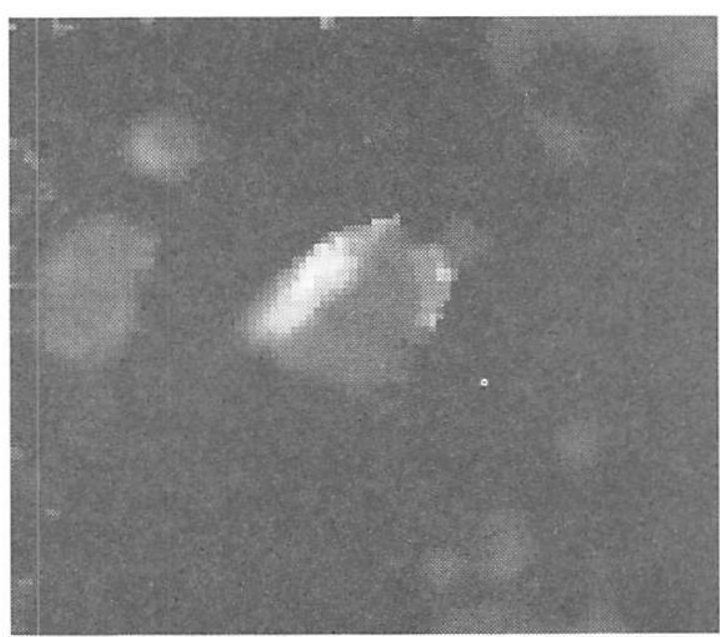

Fig. 10. $\mathrm{ND}_{32}$ image treated with pedestal and without the energy reflected from sea surface (L-5/TM: 17 April 1997).

Similar results were obtained, as shown in Fig.10, from another data observed on 17 April, 
1997. The island was easily identified by the Landsat Band4 data, however.

Therefore, it is easy to see the island and the region where the canopy of the seaweeds was on the sea surface. Results are shown in Fig.11.

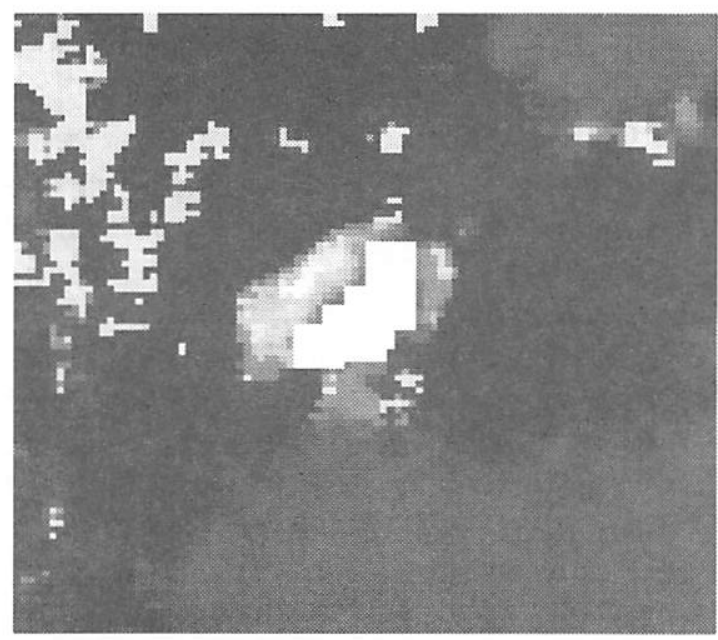

Fig.11. Identified image on island, over and under sea surface of seaweeds (L-5/TM: 16 May 1996).

\subsection{Aerial image}

The same procedures were applied to the aerial photograph which was taken at the other place. In this picture, the sea water around the island is not turbid and is much clearer than the satellite images.

Figure 12 shows the image treated by the pedestal procedure only and Fig. 13 is the image was corrected for the energy with its reflectance

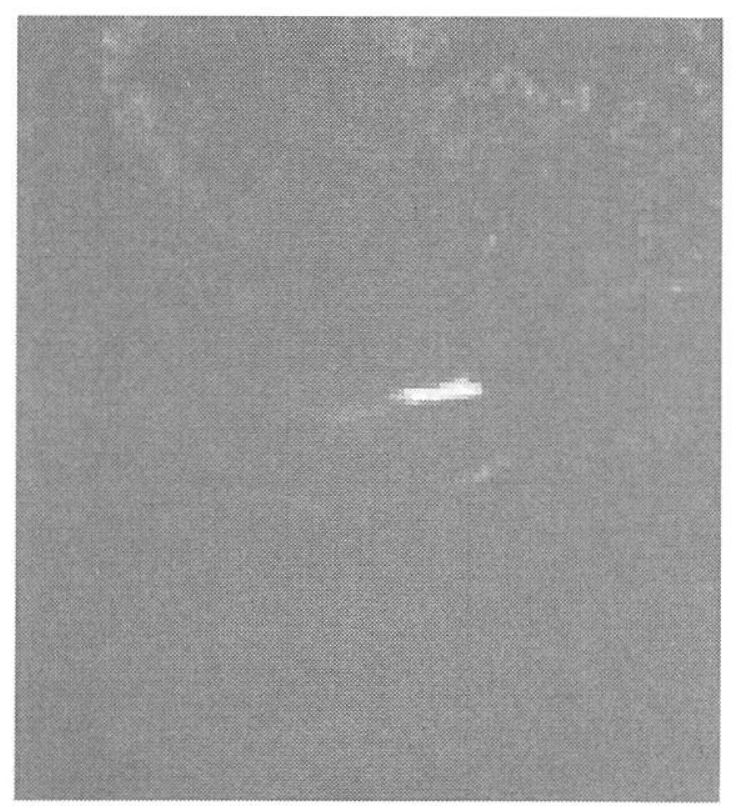

Fig.12. $N_{\mathrm{RG}}$ image of the aerial photograph treated with pedestal procedure only (26th May 2003, coastal zone of Kasari). from the fully deep sea. As the sea water was calm, the noise was negligible. As a result, a clearer image than that from the satellite data could be obtained.

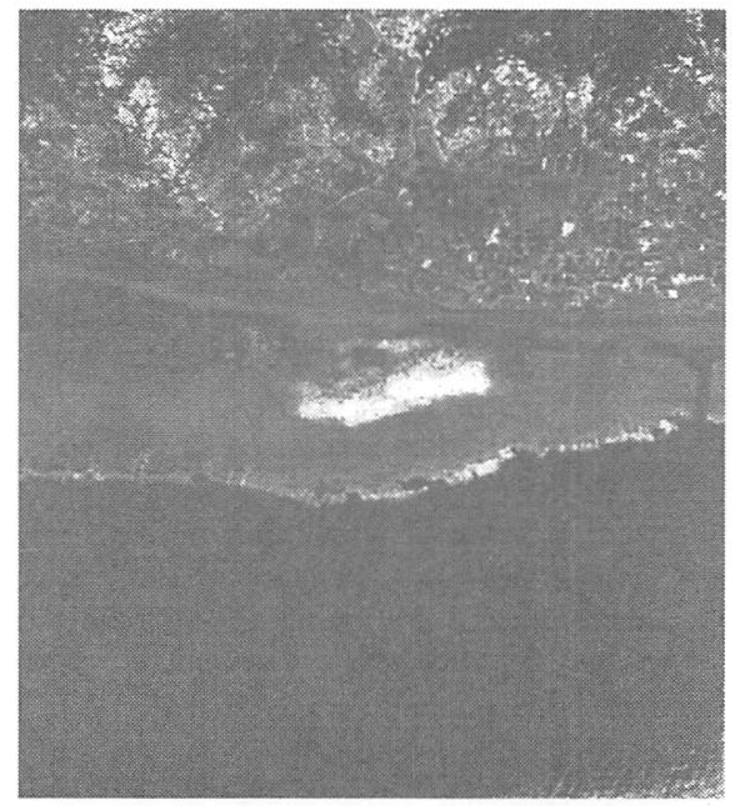

Fig.13. $\mathrm{ND}_{\mathrm{RG}}$ image of the aerial photograph treated with pedestal and without the energy reflected from sea surface (26 May 2003, coastal zone of Kasari).

\section{Conclusions}

In this study, satellite data were applied to identify seaweed-growing areas, and attempts were made to establish an effective identification method for these areas using satellite data and aerial photographs. The following results were obtained.

1) The mean spectral reflectance corresponding with Landsat TM and RGB color of seaweeds were linearly decreased with increasing a distance from the sea surface to the canopy of the seaweed.

2) It was confirmed that the indices devised from the result of the sea truth data, $\mathrm{ND}_{23}$ and $\mathrm{ND}_{\mathrm{RB}}$, are effective in identifying the areas where seaweed grows. In those cases, atmospheric effects have to be taken into account through by the pedestal procedure.

3) Moreover, it was certain that if the reflected energy from sea surface is reduced by subtracting the data at deep sea region, the accuracy of identification of the seaweeds growing spots will increase.

Since the habitat of seaweed relates to water environments, the seaweed identification methods 
proposed in this study demonstrate their potential to be used to investigate environmental changes on the seashore with satellite data and aerial photographs. We expect that these methods will give a solution to clarify the cause of environmental changes on the seashore.

Acknowledgements: This study was funded by Kagoshima University Project, Fundamental Survey for Iso-yake around Kagoshima Bay. We express our gratitude to the President of Kagoshima University at the time, Dr. Hiromitsu Tanaka.

\section{References}

Bierwirth, P.N., Lee, T.J., and Burne, R.V., 1993: Shallow Sea-Floor Reflectance and Water Depth Derived by Unmixing Multispectral Imagery. Photogram. Remote Sens. 59:331-338.

Brown, C.W., Esaias, W.E., and Thompson, A.M., 1995: Predicting Phytoplankton Composition from Space-Using the Ratio of Euphotic Depth to Mixed-Layer Depth: An Evaluation. Remote Sens. Environ. 53:172-176.

Fujii, H., Kudoh, K., Iwashita, K., Nishikawa, H., Ohki, M., and Dean, K.E., 2000: Flowing Mechanism Analysis Through Relative Turbid Level of the Lake Inbanuma -Transformed TM Data. J. Remote Sens. Soc. Japan. 20(3):71-84.

Ishiguro, E., Tatsuno, K., Kawakatsu, M., Kikukawa, H., et al., 2001: Studies on the Evaluation of Water Depth around Seashore and the Land Classification in Yap Islands Using Satellite Data. Occasional Paper, Kagoshima Univ. Research Center for the Pacific Islands, 34:77-85.

Japan Association on Remote Sensing, 1993: Remote Sensing Note. Nihon Printing Co. Ltd., Tokyo Japan

Jun, B., and Gotoh, K., 1993: Comparing and proposal of some remotely sensed bathy metric mapping method. J. Remote Sens. Soc. Japan. 13(4):41-50.

Kayane, H., 1992: Deposition of Calcium Carbonate into Holocene Reefs and its Relation to Sea-level Rise and Atmospheric $\mathrm{CO}_{2}$. Proceed. 7th Int. Coral Reef Sympo. Guam, 1992 Vol.1.

Kayane, H., Matsunaga, T., and Kanbara, H., 1994: Mapping and Monitoring Coral Reefs by Remote Sensing. Proceed. US-Japan
ASTER Science Team Meeting, November 16, 1994, Kagoshima, Japan.

Luczkovich, J.J., Wagner, T.W., and Stoffle, R.W., 1993: Discrimination of Coral Reefs, Seagrass Meadows, and Sand Bottom Types from Space; A Dominican Republic Case Study. Photogram. Remote Sens., 59(3):385-389.

Matsunaga, T., Hoyano. A., and Minakami, Y., 1999/11: Validation of the reef water depth correction algorithm using multi-temporal Landsat TM data of coral reefs on Ishigaki Island. Proceed. 27th Annual Meeting Remote Sens. Soc. Japan. 323-324.

Oki, A., Yasuoka, Y., and Tamura, M., 2001: Estimation of Chlorophyll-a and Suspended Solids Concentration in Rich Concentration Water Area with Remote Sensing Technique. $J$. Remote Sens. Soc. Japan 21(5):449-457.

Sakuno, Y., Matsunaga, T., Rokugawa, S., Takayasu, K., Kunii, H., and Nakamura, M., 2001: Monitoring Gross Primary Production at the Surface of Lake Shinji Using Multi-Date SPOT HRV Data. J. Remote Sens. Soc. Japan 21(2):141-149.

Uda, T., Murai, Y., and Takebuchi, T., 1988: Application of Satellite Remote Sensing Techniques to Coastal Survey. Material data of Civil Engineering. 30-1:2-7.

Yamano, H., Matsunaga, T., and Ikema T., 2003: Airborne hyperspectral measurement of coral reefs around Akijima, Okinawa, Japan: Autumn 2002. Proceed. 27th Annual Meeting Remote Sens. Soc. Japan. 35-36. 